\title{
ESTUDO EM MÚLTIPLAS ESCALAS TEMPORAIS DA INTENSIDADE DE RAIOS CÓSMICOS MEDIDA NA SUPERFÍCIE TERRESTRE
}

\author{
Rafael Rodrigues Souza de Mendonça ${ }^{1,2}$, Jean-Pierre Raulin ${ }^{1}$, Fernando Celso Perin Bertoni ${ }^{1}$, \\ Ezequiel Echer ${ }^{2}$, Vladimir Salingereevich Makhmutov ${ }^{3}$ e Germán Fernández ${ }^{4}$
}

Recebido em 24 junho, 2010 / Aceito em 13 outubro, 2011

Received on June 24, 2010 / Accepted on October 13, 2011

\begin{abstract}
In this work we present the analysis of the first observations of the cosmic ray intensity measured by the CARPET detector. It was installed on 2006 at Complejo Astronómico El Leoncito (CASLEO) in Argentine Andes. We present the results of the study realized between April, 2006 and February, 2010 about the long term variations in the cosmic rays related with the solar activity and the short term variations associated with the rain precipitation occurrences. Although the short operation time of the CARPET, it is observed a long term variation related with the 11-yr solar cycle. There is a gradual increase consistent with the solar activity decrease observed in this period. The analysis of transient variations related to the rainy periods indicates that changes in the atmospheric electric field also influences these short transient cosmic ray variations observed by the CARPET detector.
\end{abstract}

Keywords: cosmic rays, solar activity, atmospheric phenomena, atmospheric electric field, geomagnetic activity.

RESUMO. Neste trabalho são descritas e analisadas as primeiras observações realizadas através do detector de raios cósmicos CARPET que está instalado, desde 2006, no Complejo Astronómico El Leoncito (CASLE0) nos Andes Argentinos. Serão apresentados os primeiros estudos desenvolvidos entre abril de 2006 e fevereiro de 2010 sobre as variações de longa e de curta duração da contagem de raios cósmicos, registrada por este detector, relacionadas com a atividade solar e com a ocorrência de chuva. Apesar do pouco tempo de operação, foi possível observar com os dados do CARPET uma variação de longa duração associada ao ciclo solar de 11 anos. Há um acréscimo gradual de intensidade registrada condizente com a diminuição da atividade solar ocorrida neste período. A análise das variações transientes observadas durante períodos chuvosos evidencia que as mudanças no campo elétrico atmosférico também exercem influência nas variações transientes de curta duração na intensidade de raios cósmicos observada pelo CARPET.

Palavras-chave: raios cósmicos, atividade solar, fenômenos atmosféricos, campo elétrico atmosférico, atividade geomagnética

\footnotetext{
${ }^{1}$ Centro de Rádio Astronomia e Astrofísica Mackenzie - CRAAM, Escola de Engenharia, Universidade Presbiteriana Mackenzie, Rua da Consolação, 896, Edifício Reverendo Modesto Carvalhosa, sala 603, 01302-907 São Paulo, SP, Brasil. Tel.: (11) 2114-8734; Fax (11) 3214-2300 - E-mails: rafael@craam.mackenzie.br; raulin@craam.mackenzie.br; fbertoni@craam.mackenzie.br

2 Instituto Nacional de Pesquisas Espaciais - INPE, Av. dos Astronautas, 1758, Divisão de Geofísica Espacial, sala 28, 12227-010 São José dos Campos, SP, Brasil.

Tel.: (12) 3945-6808 - E-mails: mendonca@dge.inpe.br; eecher@dge.inpe.br

${ }^{3}$ Instituto de Física P.N. Lebedev, Academia Russa de Ciências, Leninskii pr. 53, Moscou, 119991, Rússia - E-mail: makhmutv@sci.lebedev.ru

${ }^{4}$ Complejo Astronómico El Leoncito, Consejo Nacional de Investigaciones Cientíícas y Técnicas, Av. España 1512 sur, Casilla de correo 467 J5402DSP, San Juan, Argentina - E-mail: gfernandez@casleo.gov.ar
} 


\section{INTRODUÇÃo}

Os Raios Cósmicos (RC) são partículas carregadas, principalmente prótons, dotadas de altas energias, que atingem constantemente a Terra chegando de todas as direções. 0 fluxo destas partículas, medido em nosso planeta, apresenta diversas alterações de curta e longa duração relacionadas com a atividade solar e com fenômenos ocorridos no espaço.

Acredita-se que alguns fenômenos e/ou processos ocorridos na atmosfera terrestre sejam influenciados por mudanças no fluxo de raios cósmicos que nela incidem. Assim é possível que variações na taxa de $\mathrm{RC}$ incidente na Terra, devido a algum fenômeno relacionado ao Sol, gerem ou alterem um ou mais processos físicos e químicos na atmosfera de nosso planeta. Assim, acredita-se que os raios cósmicos possam ser 0 principal meio de "comunicação" entre o Sol e a Terra, fazendo com que os fenômenos solares influenciem fenômenos ocorridos em nosso planeta (Bazilevskaya et al., 2000; Dorman, 2004).

A fim de se estudar estas relações (RC-Sol e RC-Terra) em 2006 foi posto em operação pelo Centro de Rádio Astronomia e Astrofísica Mackenzie (CRAAM) o detector de raios cósmicos CARPET no Complejo Astronómico El Leoncito (CASLE0) na província de San Juan na Argentina, através de uma colaboração entre estes dois e o Instituto de Física P.N. Lebedev (LPI) da Rússia.

\section{RELAÇÕES ENTRE OS RAIOS CÓSMICOS, O SOL E A TERRA}

Os RC são estudados desde o final do século XIX, época em que eles foram descobertos. Inicialmente acreditava-se que eles eram um tipo de radiação eletromagnética, mas atualmente já se sabe que os RC são partículas carregadas, na maioria prótons, de energia superior a $1 \mathrm{MeV}$.

Os raios cósmicos costumam ser classificados em primários e secundários. Os primários são as partículas cósmicas que se encontram no espaço. Já os raios cósmicos secundários são as partículas resultantes da colisão das partículas primárias, que incidiram na Terra, com átomos ou moléculas presentes na atmosfera terrestre (Otaola \& Valdés-Galicia, 1992).

De acordo com a sua origem, os raios cósmicos primários podem ser chamados de: Raios Cósmicos Galácticos, Solares ou Anômalos. Os Raios Cósmicos Galácticos são, entre os três tipos, os que apresentam maior fluxo e maior energia. Eles são isotrópicos e incidem na Terra de forma contínua, porém não constante. Sua origem e mecanismo de aceleração não são conhecidos, existindo apenas hipóteses sobre este assunto. Os
Raios Cósmicos Solares são partículas de grande energia provenientes do Sol que ocorrem de forma ocasional. Essas partículas são aceleradas em processos de físicos ocorridos nas explosões solares ou através da aceleração de partículas carregadas pela onda de choque existente entre uma ICME (Ejeção de Massa Coronal Interplanetária - Interplanetary Coronal Mass Ejection) e 0 meio interplanetário. Os Raios Cósmicos Anômalos são os que apresentam o menor fluxo e acredita-se que eles sejam gerados através da interação entre 0 gás interestelar neutro, 0 vento solar e a onda de choque existente na região da heliopausa (Mursula \& Usoskin, 2003).

Além da produção de forma esporádica de raios cósmicos solares, que é vista por detectores na Terra como um aumento momentâneo na contagem de partículas cósmicas, existem variações no fluxo de raios cósmicos ocorridas devido à interação entre 0 Sol e os Raios Cósmicos Galácticos. Uma das principais é a anticorrelação entre a intensidade de raios cósmicos e o ciclo de atividade solar de 11 anos, que consiste em uma mínima contagem de partículas cósmicas medido em nosso planeta durante a alta atividade solar e uma máxima contagem durante a baixa atividade solar. Esta variação na contagem de raios cósmicos pode estar relacionada com o fato de que durante o período de máxima atividade solar o campo magnético do Sol apresenta-se mais conturbado, o que dificulta a entrada dos raios cósmicos galácticos na heliosfera. Há também uma variação na contagem de partículas cósmicas relacionada ao ciclo de 22 anos do campo magnético solar que está ligada à diferença no caminho percorrido pelos raios cósmicos galácticos na heliosfera durante períodos de polaridades diferentes do Sol (Jokipii et al., 1977; Stozhkov et al., 2001; Singh \& Badruddin, 2006).

Outra importante variação no fluxo de raios cósmicos relacionada à atividade solar é a conhecida como decréscimo de Forbush. Estes eventos consistem na queda brusca da contagem de raios cósmicos associada à passagem de uma concentração de massa ejetada pelo Sol (uma ICME) sobre a Terra, apresentando um lento retorno para a contagem normal, que pode chegar a durar dias (Forbush \& Van Allen, 1994). Acredita-se que o decréscimo de Forbush também possa ser gerado pela passagem de uma onda de choque existente entre uma ICME e o meio interplanetário, não havendo assim a necessidade da passagem da ICME sobre a Terra, logo há também a possibilidade que os decréscimos sejam gerados pela junção destes dois eventos (Cane, 1996, 2000).

Como são compostos por partículas de carga não nula, os raios cósmicos são afetados por campos elétricos e magnéticos. 0 campo magnético solar funciona como um "escudo" contra os raios cósmicos galácticos de baixa energia, ou seja, impede 
ou dificulta a entrada na heliosfera destas partículas devido às alterações que gera em suas trajetórias. Da mesma forma o campo geomagnético restringe a entrada de partículas cósmicas na atmosfera terrestre.

De forma generalizada, a intensidade de raios cósmicos é mínima no equador, enquanto que nos pólos este fluxo apresenta seu valor máximo. Esta maior intensidade nas regiões polares ocorre pelo fato de 0 campo magnético terrestre não apresentar influência sobre as partículas que incidem verticalmente sobre essas regiões (Ziegler, 1998).

A grandeza física que está relacionada à capacidade de uma partícula cósmica conseguir passar ou não pelo campo geomagnético é denominada rigidez geomagnética. Para se calcular a rigidez geomagnética de um dado local na Terra para uma dada partícula cósmica, além da relação com 0 campo geomagnético se é considerada a relação com os processos ocorridos pela passagem desta partícula na atmosfera. Desta maneira, a rigidez geomagnética costuma ser definida como a menor energia que um próton (raio cósmico primário) incidindo em um dado local na atmosfera terrestre através de uma dada trajetória deve possuir para que os raios cósmicos secundários provenientes de sua entrada possam ser observados em uma determinada altitude (Rossi, 1964; Ziegler, 1996).

Devido às interações ocorridas entre as partículas cósmicas e 0 campo geomagnético, existe, para cada ponto da superfície terrestre e para cada faixa de energia dos raios cósmicos, um cone (o chamado cone de Störmer) de direções proibidas, que no caso das partículas serem positivas apontam pra leste e no caso das partículas serem negativas aponta para leste. A conclusão de que os raios cósmicos eram compostos somente de partículas positivas ocorreu quando medidas direcionais do fluxo de raios cósmicos na superfície terrestre mostraram que havia um maior fluxo vindo a oeste do ponto de observação, mostrando através dos cones de Störmer que as partículas cósmicas eram positivas.

Após a interação com o campo magnético terrestre, os raios cósmicos primários de altas energias, que não foram desviados e seguiram em direção a Terra, têm uma grande probabilidade de colidir com algum átomo que esteja presente na atmosfera. Esta colisão gera uma cadeia de processos, que recebe 0 nome de Chuveiro de Raios Cósmicos, onde são geradas diversas partículas chamadas de Raios Cósmicos Secundários (Otaola \& Valdés-Galicia, 1992).

As partículas produzidas neste chuveiro podem ser divididas em três componentes: a componente nucleônica, a componente eletromagnética e a componente méson-muônica. Na colisão entre uma partícula primária e um átomo presente na atmosfera podem ser gerados: prótons, nêutrons e píons neutro, negativos e positivos.

Os nucleons formados nesta colisão inicial podem colidir com átomos da atmosfera e gerar mais prótons e nêutrons que podem seguir o mesmo processo formando outros nucleons, gerando uma cadeia de desintegrações nucleares onde são formados prótons e nêutrons que são os constituintes da componente nucleônica. Os píons de carga não nula gerados na colisão da partícula primária e, em casos raros, gerados pela colisão de prótons da componente nucleônica, pertencem à componente méson-muônica que também é composta por neutrinos e múons formados pelo decaimento dos píons negativos ou positivos. Já a componente eletromagnética é formada por elétrons, pósitrons e fótons provenientes do decaimento de píons neutros e de múons e de outros processos de menor importância, como ionização, produção de pares e cascatas fóton-elétron.

0 fluxo de raios cósmicos secundários varia com a altura, apresentando um pico em torno dos $15 \mathrm{~km}$ de altitude, região onde se dá a maior produção de partículas secundárias, decaindo suavemente para alturas menores e caindo de forma mais drástica para alturas superiores a $15 \mathrm{~km}$.

Apesar dos múons possuírem um tempo de meia vida em repouso pequeno (aproximadamente $2 \times 10^{-6}$ segundos), eles são detectados a grandes distâncias do local onde se deu a colisão inicial, devido à sua velocidade muito próxima à da luz.

A interação entre os raios cósmicos e a atmosfera da Terra ocorre de forma mútua, ou seja, os raios cósmicos podem influenciar alguns fenômenos ocorridos na atmosfera e, por outro lado, existem fenômenos e processos ocorridos na atmosfera que podem produzir variações no fluxo de raios cósmicos registrado por detectores localizados na superfície terrestre.

Um dos principais efeitos da atmosfera na contagem de raios cósmicos é 0 Efeito Barométrico, que consiste na anticorrelação entre 0 fluxo de raios cósmicos e a pressão atmosférica. Ele ocorre devido ao menor livre caminho médio das partículas cósmicas na atmosfera quando há uma maior pressão por causa do aumento das colisões entre as partículas cósmicas e partículas da atmosfera, havendo um maior livre caminho médio no caso de uma menor pressão (Famoso et al., 2005).

As alterações no campo elétrico atmosférico devido a presença de nuvens de tempestades eletricamente carregadas podem acelerar as partículas cósmicas secundárias, principalmente elétrons, acarretando em um aumento na contagem de raios cósmicos em alguns detectores (Dorman, 2004; Khaerdinov et al., 2005). 


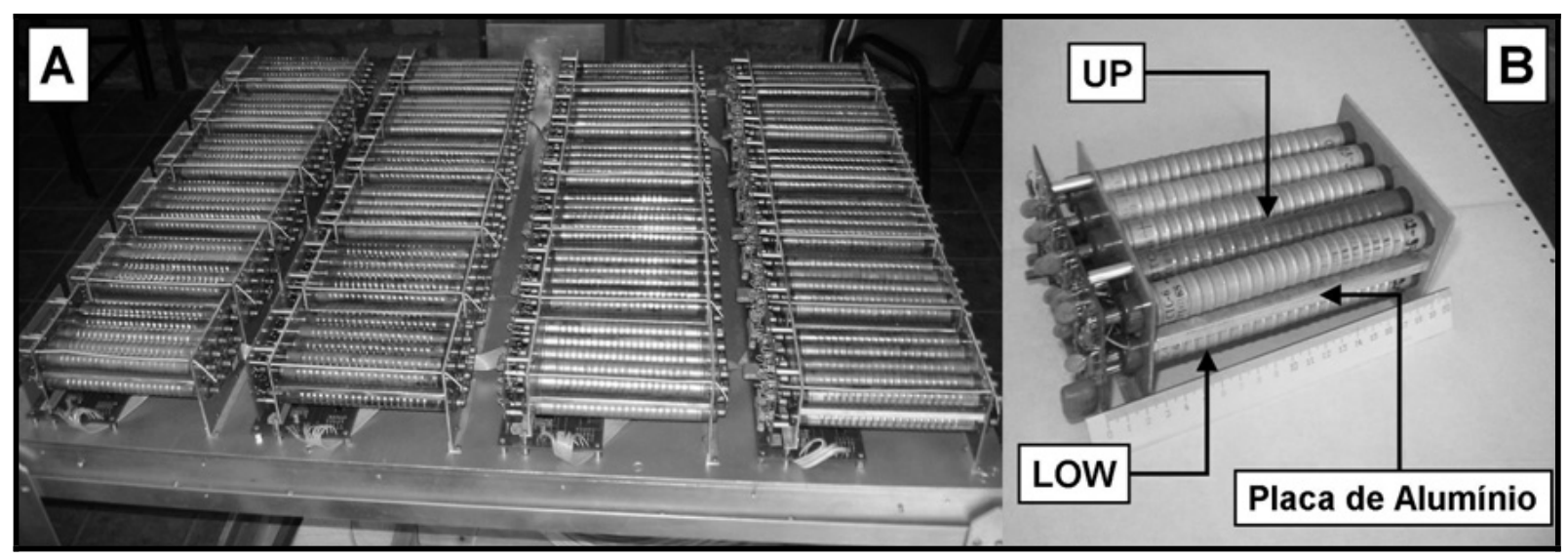

Figura 1 - A: Os 24 blocos com 10 detectores cada, formadores do CARPET. B: configuração de cada bloco indicando a posição da placa de alumínio e dos detectores formadores do sinal UP e LOW.

Outros dois fenômenos atmosféricos que podem produzir alterações na contagem de raios cósmicos são as mudanças na temperatura da atmosfera e as chuvas. A influência da temperatura no fluxo de raios cósmicos se dá de forma complexa estando relacionada com variações de temperaturas ao longo de diferentes altitudes na atmosfera. As variações de longa duração na contagem de partículas cósmicas relacionadas com a temperatura podem ser explicadas, de maneira simplificada, como 0 aumento do caminho percorrido pelos múons, durante 0 aquecimento e expansão da atmosfera na passagem do inverno para 0 verão, o que aumenta a taxa total de decaimento destas partículas resultando num menor fluxo a baixas altitudes (Dorman, 2004).

No caso das chuvas, pode ocorrer um aumento da contagem de raios cósmicos em detectores sensíveis a radiação gama. Isto ocorre devido ao aumento da radioatividade natural ambiente durante as chuvas, que acontece pelo fato de a água da chuva trazer consigo átomos bastante radioativos, como do de $\mathrm{Rb}-222$, da atmosfera para o solo (Nishikawa et al., 2000; Merier et al., 2009).

De forma geral, os efeitos da atmosfera no fluxo de raios cósmicos ocorrem de forma localizada e variam de detector para detector. No entanto, é de grande importância para 0 estudo da influência dos raios cósmicos em fenômenos atmosféricos 0 conhecimento da influência dos fenômenos atmosféricos na contagem de raios cósmicos medida na superfície de nosso planeta.

A mais conhecida influência dos raios cósmicos na atmosfera ocorre no processo de produção de íons entre 3 e $60 \mathrm{~km}$ de altitude. Devido a esta relação, acredita-se que grandes variações no fluxo de raios cósmicos devido ao ciclo solar de 11 anos possam influenciar a concentração de ozônio da atmosfera e o efeito estufa (Bazilevskaya et al., 2000).
Também há algumas evidências de que a ocorrência de chuvas possa ser influenciada pelo fluxo de partículas cósmicas. Estudos observaram que há uma diminuição, em relação à média, do índice de chuvas no dia em que houve uma queda no fluxo de raios cósmicos devido a um evento Forbush. Da mesma forma, também se foi observado que há um aumento no índice de chuvas em períodos onde ocorreu um aumento na contagem de raios cósmicos devido a uma ejeção de raios cósmicos solares (Stozhkov et al., 1995, 2001).

Estudos recentes mostraram que no último ciclo solar a variação da cobertura global de nuvens em nosso planeta ocorreu em fase com a variação do fluxo de raios cósmicos relacionada com o ciclo de atividade solar, o que indica uma provável contribuição dos raios cósmicos na formação de nuvens (Svensmark, 2000).

\section{O DETECTOR DE RAIOS CÓSMICOS CARPET}

Com o objetivo de se estudar estas relações entre os raios cósmicos, o Sol e a Terra foi instalado em 2006 no Complejo Astronómico El Leoncito (CASLE0), em uma altitude de $2552 \mathrm{~m}$ (rigidez geomagnética média de 12 GV) 0 detector de raios cósmicos CARPET, que possui este nome devido ao seu formato semeIhante ao de um tapete.

0 CARPET, que pode ser observado na Figura 1-A, tem aproximadamente $2 \mathrm{~m}^{2}$ de área e consiste em um conjunto de 24 blocos de 10 detectores do tipo Geiger de forma cilíndrica com diâmetro de 1,9 cm e comprimento de 9,8 cm. Em cada bloco, como é mostrado na Figura 1-B, cinco detectores se encontram acima de uma placa de alumínio de 0,7 cm de espessura e cinco se encontram abaixo desta placa. 


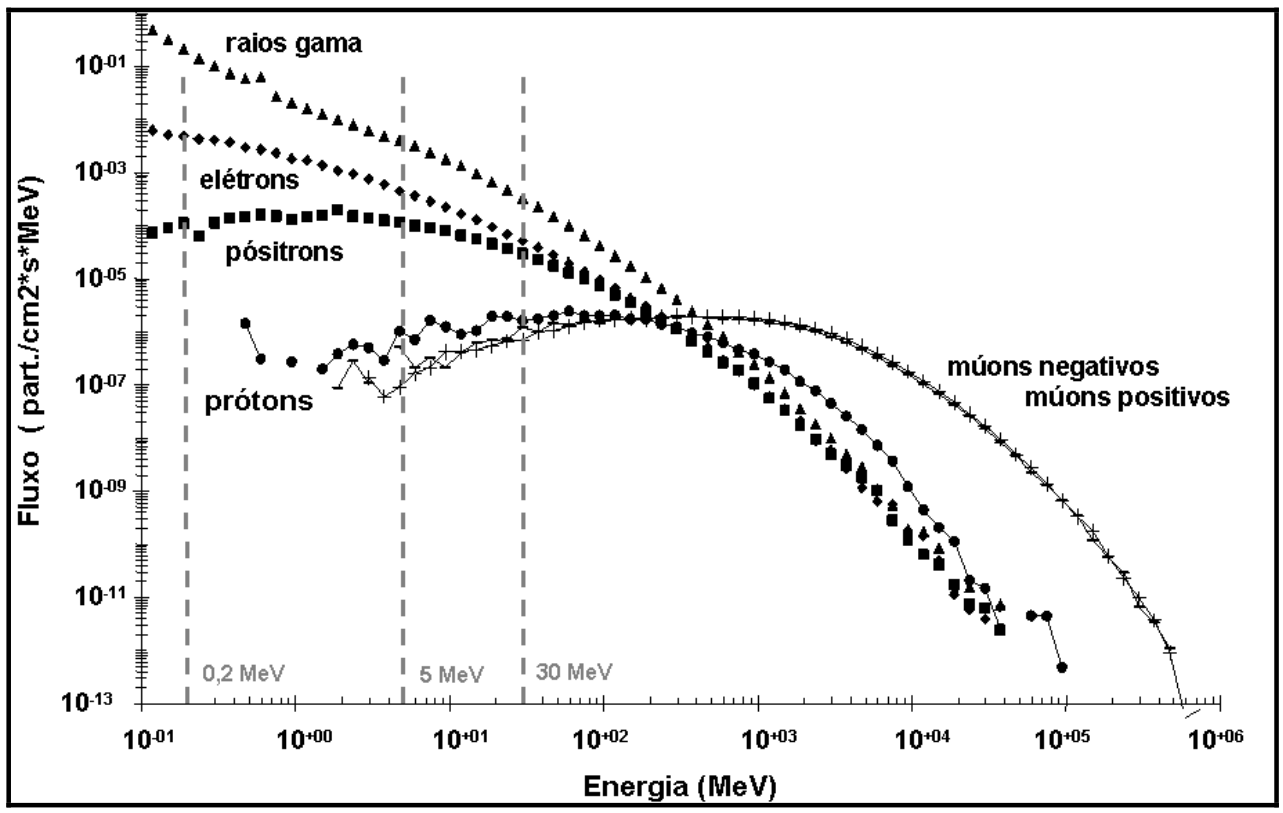

Figura 2 - Espectro de energia nas condições do local onde está instalado CARPET obtido através da simulação de Monte Carlo. As duas primeiras linhas tracejadas verticais indicam respectivamente 0 valor de menor energia de elétrons e prótons detectados nos sinais UP e LOW. A penúltima e a última linhas tracejadas verticais indicam respectivamente 0 valor de menor energia de elétrons e prótons detectados no sinal TELESCOPE.

0 CARPET apresenta três sinais de dados chamados de UP, LOW e TELESCOSPE. 0 sinal UP corresponde à somatória das contagem registrada nos detectores que se encontram acima da placa de alumínio, enquanto 0 sinal LOW corresponde à somatória da contagem registrada nos detectores que ficam abaixo da placa. Já o sinal TELESCOPE corresponde à somatória das partículas que foram detectadas em um detector superior (acima da placa de alumínio) e seu correspondente abaixo da placa de alumínio quase que simultaneamente. Cada detector realiza sua contagem de partículas em intervalos de $500 \mathrm{~ms}$, no entanto 0 CARPET tem a capacidade de alterar seu tempo de medição entre 0 intervalo de $250 \mathrm{~ms}$ a 10 s.

Os sinais UP e LOW possuem a capacidade de detectar elétrons com energias maiores que $0,2 \mathrm{MeV}$, prótons com energia superior a $5 \mathrm{MeV}$ e, com uma eficiência menor que 1\%, raios$\gamma$ com energia acima de $0,02 \mathrm{MeV}$ vindos de qualquer direção. Enquanto que o sinal TELESCOPE não é sensível a radiação gama e possui a capacidade de detectar elétrons com energia acima de $5 \mathrm{MeV}$ e prótons com energia acima de $20 \mathrm{MeV}$, que tenham incidido quase verticalmente sobre 0 instrumento.

Através do espectro de energia das partículas cósmicas nas condições do local onde o CARPET está instalado (rigidez geomagnética de 9,8 GV e pressão atmosférica média de $800 \mathrm{~g} / \mathrm{cm}^{2}$ ) calculado através da simulação GEANT4 baseada no método de
Monte Carlo (Metropolis \& Ulam, 1949), mostrado na Figura 2, é possível se observar 0 grande fluxo de fótons para baixas energias (superiores a $0,02 \mathrm{MeV}$ ). No entanto, devido à baixa sensibilidade a radiação gama, os sinais UP e LOW são mais influenciados pelos elétrons na faixa de energia menor que $1 \mathrm{GeV}$. Também é possível se observar que o fluxo de elétrons não é muito significativo no sinal TELESCOPE em relação às outras partículas e que para grandes energias $(>1 \mathrm{GeV}$ ) a contagem dos três sinais estará mais influenciada pelo fluxo de múons.

\section{O CARPET E A ATIVIDADE SOLAR}

Apesar de seu pouco tempo de funcionamento (um pouco mais que 4 anos) já se é possivel observar a anticorrelação entre a contagem de raios cósmicos registrada pelo CARPET e a atividade solar. Na Figura 3, que mostra a contagem de raios cósmicos registrado no sinal TELESCOPE e o fluxo em rádio ( $\mathrm{F} 10,7 \mathrm{~cm}$, observado pelo Dominion Radio Astrophysical Observatory) emitido pelo Sol desde abril de 2006, é possível se observar que enquanto o fluxo solar em rádio apresenta uma diminuição, a média da contagem de raios cósmicos (linha tracejada) apresenta um aumento. Já, desde meados de 2009, enquanto a atividade solar aumenta, há uma queda na contagem média de raios cósmicos. 


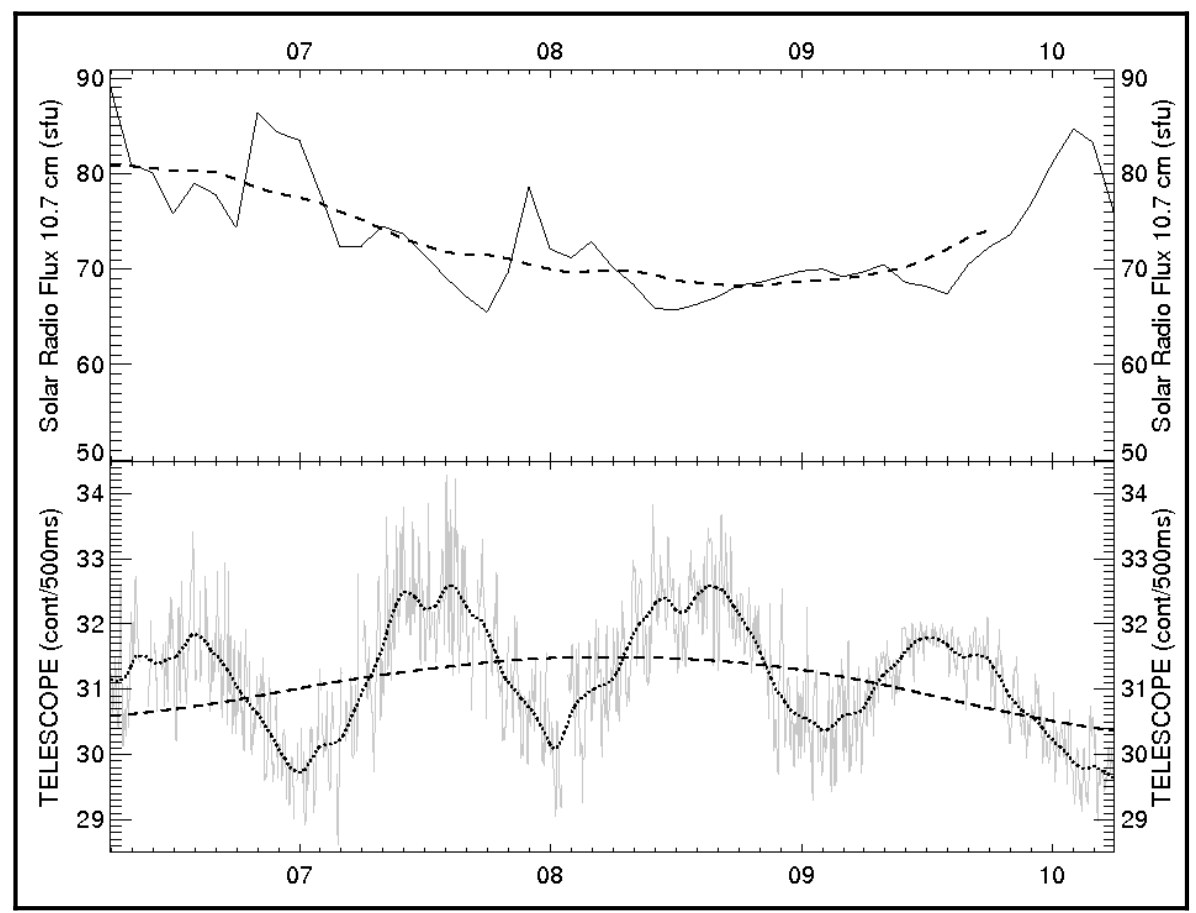

Figura 3 - Representação no quadro superior da variação da radiação solar em rádio $(\lambda=10,7 \mathrm{~cm})$ emitida pelo Sol e, no quadro inferior, a média diária (linha cinza contínua), a média mensal (linha pontilhada) e a média a cada 15 meses (linha tracejada) da contagem de raios cósmicos registrada no sinal TELESCOPE entre abril de 2006 e abril de 2010.

Na Figura 3 também é possível se observar uma variação sazonal da contagem de raios cósmicos com período de aproximadamente seis meses, com valor máximo observado em torno de agosto e mínimo próximo de janeiro. Essa variação ocorre possivelmente devido à mudança de temperatura atmosférica ocorrida no mesmo período. 0 aumento de temperatura provoca uma expansão da atmosfera que implica num maior caminho a ser percorrido pelos raios cósmicos que devido a isto sofrerão mais colisões e decaimentos apresentando um menor fluxo em baixas altitudes.

É possível se notar que o valor mínimo e máximo da variação sazonal, mostrada na Figura 3, se altera com o tempo. 0 mínimo valor da contagem de raios cósmicos registrado nos meses de verão é maior em 2009 do que em 2006, no entanto com o aumento da atividade solar em 2010, o valor mínimo neste ano é menor que 0 de 2009.

No dia 6 de dezembro de 2006 ocorreu uma ejeção de partículas de altas energias pelo Sol (raios cósmicos solares), que pode ser observada na Figura 4 como um aumento, ocorrido principalmente nos sinais UP e LOW, na contagem de raios cósmicos por volta das 22:00 UT deste dia, período de mínima contagem da variação diária que apresenta valor máximo às $\sim 18$ horas locais (LT) e valor mínimo às $\sim 5 \mathrm{LT}$.
Este aumento no fluxo de raios cósmicos ocorreu no mesmo período em houve um aumento no fluxo de prótons com energia superior a $100 \mathrm{MeV}$ (curva contínua no quadro superior) observado pelo satélite GOES-12, relacionado a uma grande explosão solar ocorrida no mesmo dia às 18:29 UT que pode ser vista pelo aumento no fluxo de raios $X$ emitidos pelo Sol que é mostrado pela curva pontilhada no quadro superior da Figura 4.

0 CARPET desde 0 início de seu funcionamento até a presente data atuou em um período de baixa atividade solar. No entanto, foram observadas variações na contagem de raios cósmicos por ele registrada associadas a distúrbios magnetosféricos (tempestades e subtempestades) indicadas por diminuições no índice Dst e aumentos do índice Kp relacionados à passagem de uma ICME sobre a Terra, como é o caso do evento mostrado na Figura 5. Neste evento é possível se ver que a queda no índice Dst que apresentou um mínimo de aproximadamente $-50 \mathrm{nT}$ e 0 aumento no índice Kp (máximo de 7) estão associados a uma queda na intensidade de partículas registrada no sinal TELESCOPE. De maneira geral, os eventos observados não foram acompanhados de grandes tempestades geomagnéticas, indicadas por grandes variações no índice Dst e Kp.

A relação entre a queda no fluxo de raios cósmicos e a atividade geomagnética relacionada com as ejeções de massa 


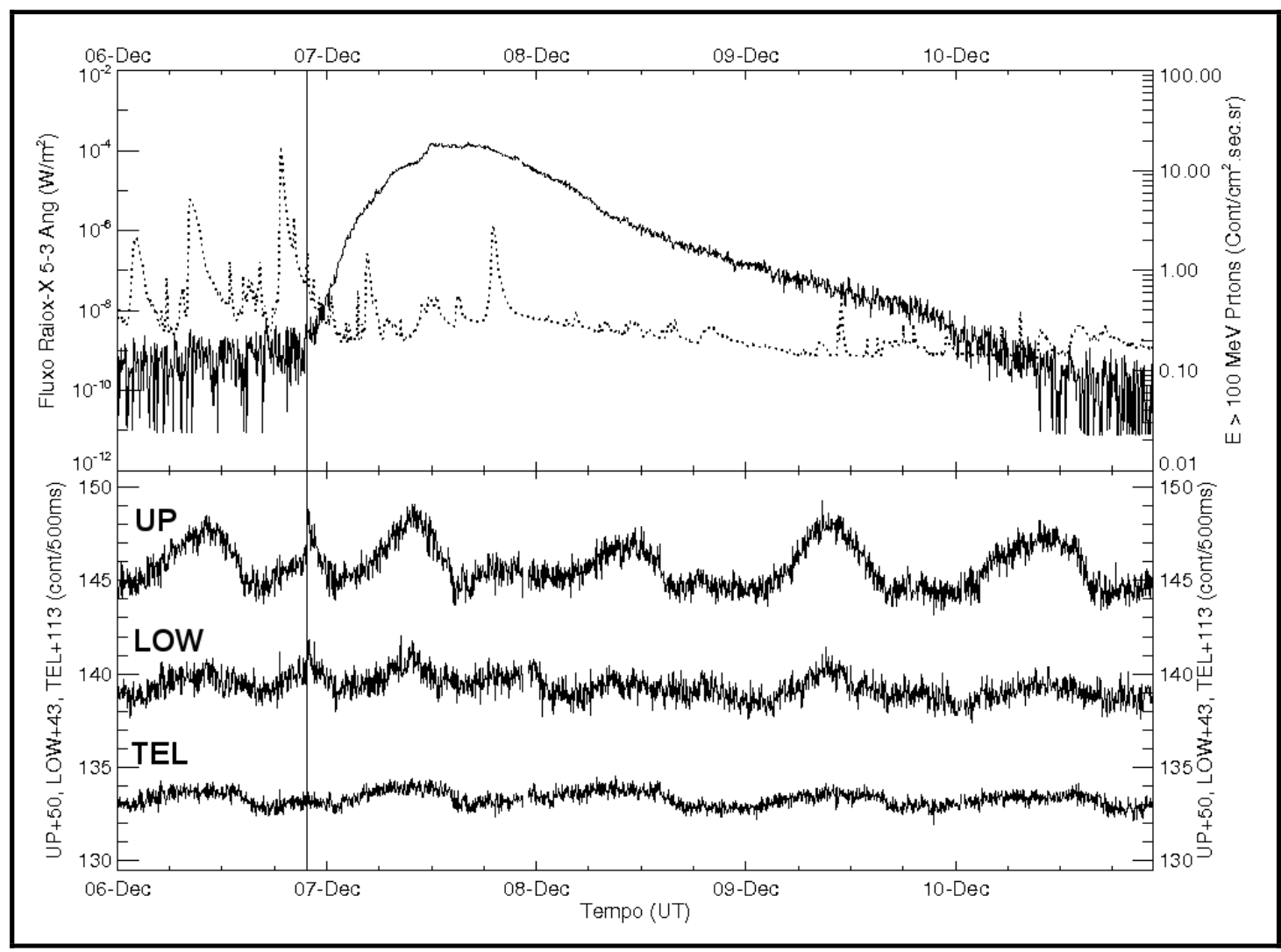

Figura 4 - Aumento na contagem média (1 minuto) de raios cósmicos nos três sinais do CARPET durante um período de mínima contagem da variação diurna, ocorrida durante uma explosão solar no dia 6 de dezembro de 2006 às 18:29 UT (linha vertical) indicada pelo aumento no fluxo de raios X (linha pontilhada quadro superior) que produziu um amento na presença de prótons com energia superior a $100 \mathrm{MeV}$ (linha contínua quadro superior).

coronal não é simples. Existem casos em que as perturbações geomagnéticas não estão relacionadas com a passagem de uma ICME sobre a Terra. Uma grande variação do índice Dst pode ser acompanhada por uma queda brusca na contagem de raios cósmicos, por uma queda gradual ou, até mesmo, pode ser acompanhada por nenhuma variação no fluxo de raios cósmicos (Kudela \& Brenkus, 2004).

\section{O CARPET E OS FENÔMENOS ATMOSFÉRICOS}

Para facilitar o estudo da relação entre o fluxo de raios cósmicos e outros fenômenos, é feita uma correção nos dados do CARPET eliminando a influência da pressão atmosférica na contagem de raios cósmicos registradas nos três sinais deste detector.

A relação entre a variação da pressão atmosférica e a variação na intensidade de raios cósmicos para detectores do tipo Geiger, como o CARPET, no caso de pequenas variações na pressão atmosférica é dada pela Equação (1):

$$
\frac{\Delta I}{I}=\beta \cdot \Delta P+\alpha
$$

sendo: $\Delta I$ a variação da intensidade de raios cósmicos em relação à média, $I$ a intensidade média de raios cósmicos, $\Delta P$ a variação da pressão atmosférica em relação à pressão média e $\beta$ o coeficiente barométrico, que apresenta valor negativo devido à anticorrelação entre estes dois parâmetros.

Conforme é mostrado na Figura 6, correlacionando-se a variação relativa da contagem de raios cósmicos e a variação de pressão em períodos de baixa atividade solar e geomagnética, para cada sinal do CARPET, foi obtido, através de uma reta média, os seus respectivos coeficientes barométricos.

Para 0 sinal UP $\beta=-0,35 \% / \mathrm{hPa}$, para 0 LOW $\beta=$ $-0,33 \% / \mathrm{hPa}$ e para 0 sinal TELESCOPE $\beta=-0,44 \% / \mathrm{hPa}$. Através destes coeficientes é possível se saber quanto é a influência que as mudanças de pressão geram na contagem de raios cósmicos, assim é possível corrigir os dados, eliminandose esta influência da contagem registrada pelo CARPET. A Figura 7 mostra a diferença entre os dados não corrigidos (quadro superior) e os dados corrigidos (quadro inferior) durante o mês de março de 2010. 


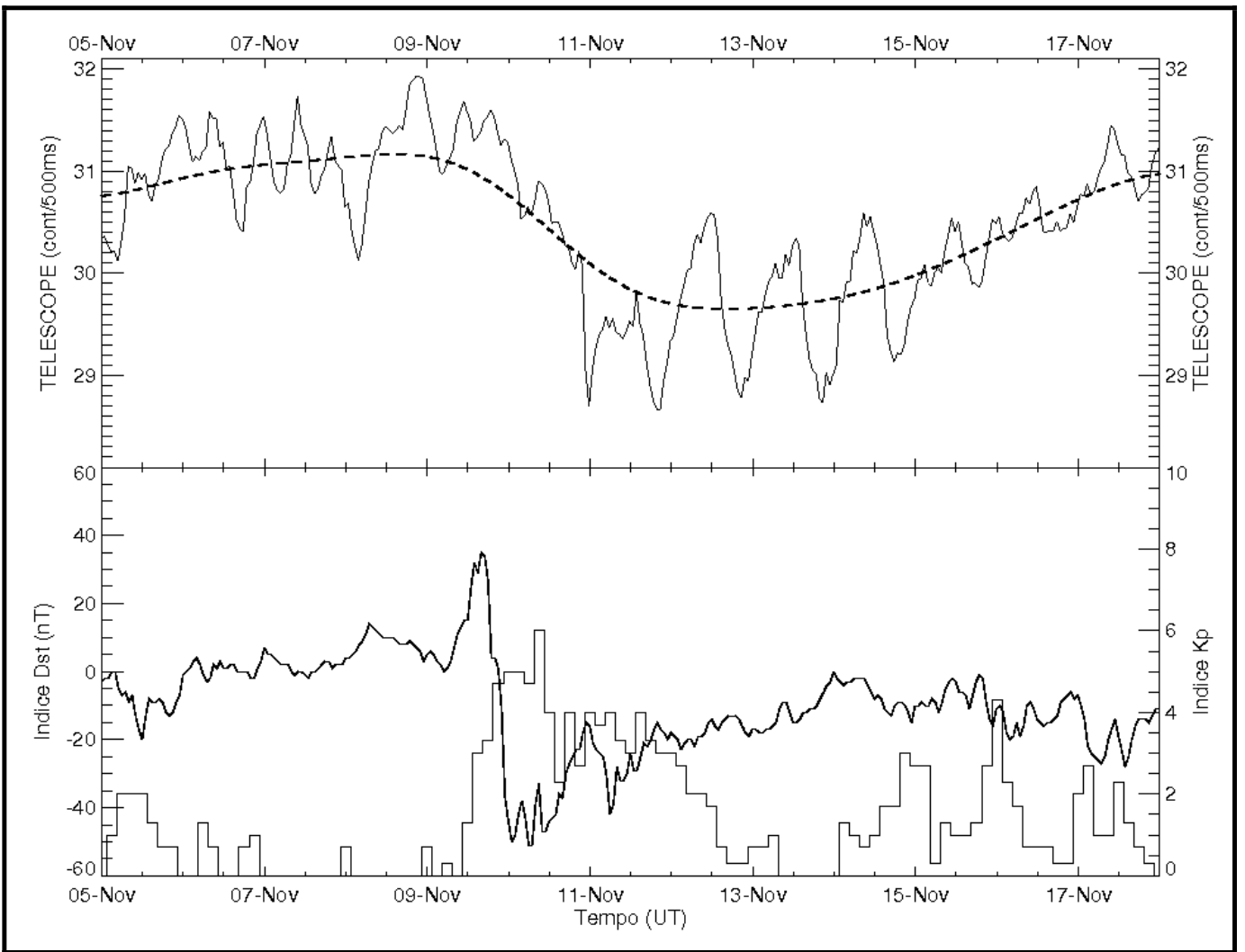

Figura 5 - Quadro Superior: média corrida horária (linha contínua) e diária (linha tracejada) da contagem de raios cósmicos registrada no sinal TELESCOPE entre 05/11/2006 às 00:00 e 18/11/2006 às 00:00. Quadro Inferior: Índice Dst, linha contínua, e Kp, histograma, medidos no mesmo período.

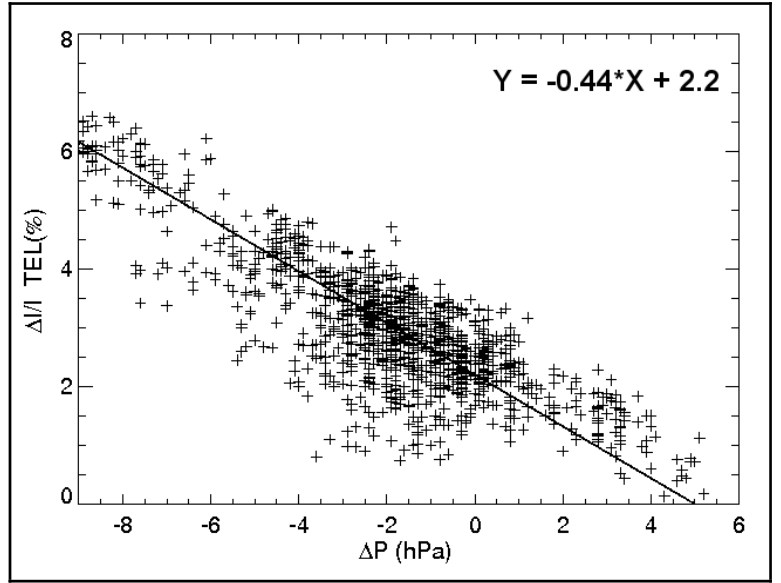

Figura 6 - Correlação entre a variação relativa da contagem de raios cósmicos $(\Delta I / I)$ e a variação de pressão $(\Delta P)$, para os sinais UP, LOW e TELECOPE calculadas através dos dados coletados em julho de 2009

0 CARPET, por ter dois sinais capazes de detectar radiação gama apresenta, nestes dois sinais, variações na contagem observada durante períodos de chuvas. Como é mostrado na Figura 8 , há um aumento na contagem dos sinais UP e LOW nos períodos de chuva, enquanto a contagem no sinal TELESCOPE permanece sem alterações, pois este sinal não é sensivel a radiação gama.

Apesar da baixa sensibilidade $(<1 \%)$ a radiação gama dos sinais UP e LOW, o aumento na contagem de raios cósmicos durante algumas chuvas é bastante significativo. A Figura 9 mostra um exemplo do aumento da contagem, no sinal UP devido à ocorrência de chuva ocorrido no mês de outubro de 2008. Nesta figura é possível se observar a clara diferença na contagem pelo sinal UP entre o período de chuva (entre os dias 25 e 26) e os outros dias do mês onde não houve a ocorrência de chuvas.

Entre abril de 2006 e março de 2010 foram observados cerca de 130 eventos, onde foi observada uma variação na contagem de raios cósmicos nos sinais sensíveis a radiação gama no mesmo período em que foi registra a ocorrência de chuva.

Em uma análise preliminar dos eventos simples (como mostrado na Fig. 8) comparou-se o valor da integral da contagem de raios cósmicos do sinal UP entre 0 início do aumento e 0 tempo em que se deu a máxima contagem (que corresponde à área de cor 


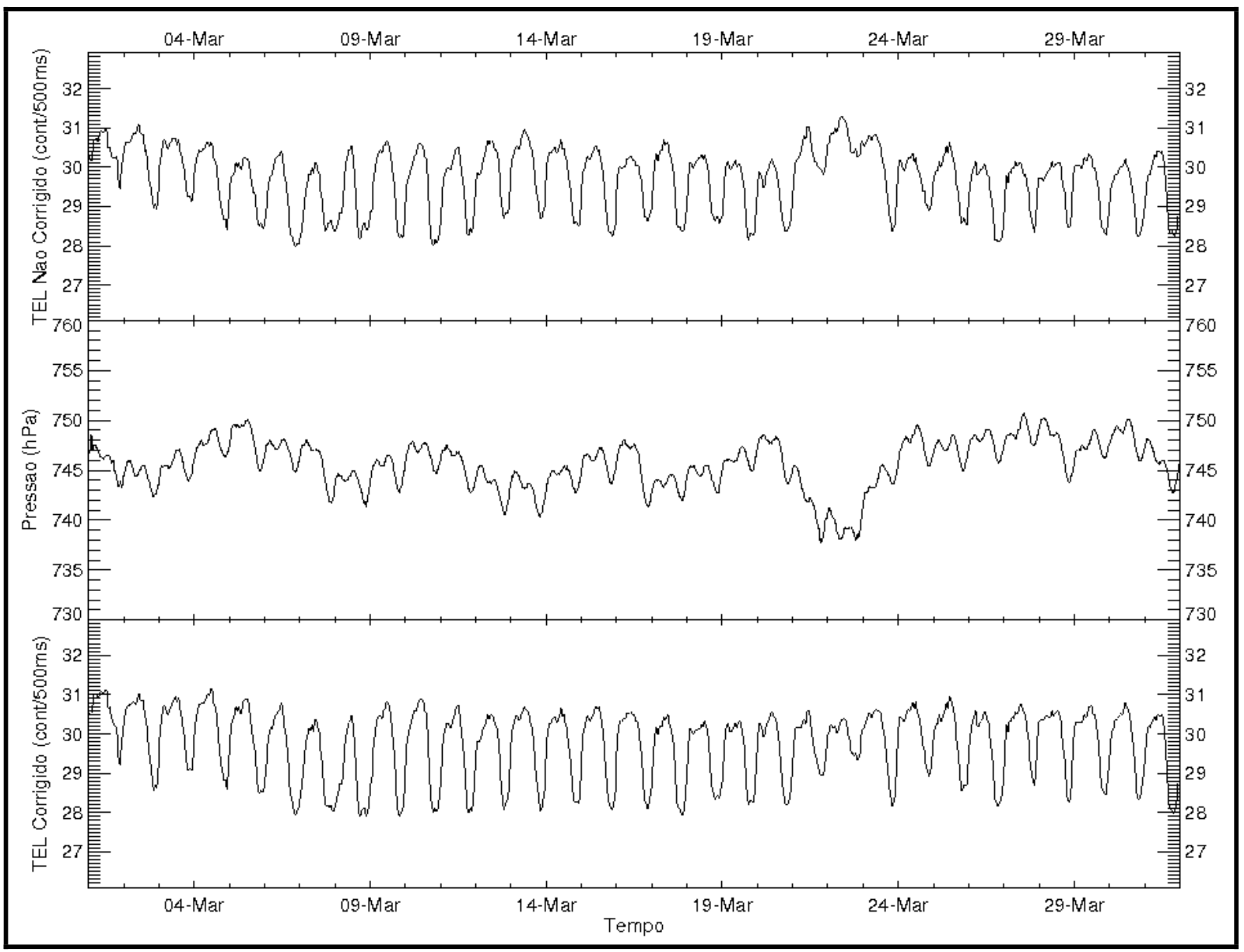

Figura 7 - Comparação entre os dados não corrigidos ( $1^{\circ}$ quadro) e os dados corrigidos ( $3^{\circ}$ quadro) registrados pelo CARPET para uma dada variação de pressão ( $2^{\circ}$ quadro) ocorrida no mês de março de 2010.

cinza na Fig. 8) e a somatória das medidas de chuva registradas no mesmo período.

A análise destes parâmetros indica a presença de duas tendências diferentes entre as chuvas e as variações no fluxo de raios cósmicos nos sinais UP e LOW, mostradas na Figura 10. Isto pode indicar a atuação de processos físicos diferentes, ou seja, que durante a ocorrência de chuvas não é somente a radiação natural da água que apresenta influência na contagem de raios cósmicos.

Há variações de curta duração (de algumas horas) na contagem de raios cósmicos registrada nos sinais UP e LOW, semelhantes às variações ocorridas durante as chuvas, porém sem a ocorrência delas. Estas variações, como mostra a Figura 11, estão relacionadas com mudanças no campo elétrico atmosférico devido à presença de nuvens eletricamente carregadas. Nesta figura, é possível se observar que há um aumento no fluxo de raios cósmicos nos sinais UP e LOW ocorrido juntamente com 0 aumento do campo elétrico atmosférico.

Logo, as variações no campo elétrico atmosférico durante as chuvas podem causar variações na contagem de raios cósmicos que se somariam as alterações produzidas pelas chuvas, fazendo com que chuvas de mesma intensidade, porém com variações de campo elétrico diferentes sejam acompanhadas de variações de intensidades diferentes na contagem de raios cósmicos, explicando-se as tendências encontradas na Figura 10.

Grandes variações na intensidade do campo elétrico atmosférico, além de influenciarem na contagem dos sinais de menor energia (UP e LOW), podem causar um aumento de partículas de maior energia, produzindo variações na contagem registrada pelo sinal TELESCOPE, que não é sensível a radiação gama, e por isso não apresenta variações em sua contagem relacionada com a ocorrência de chuva. 


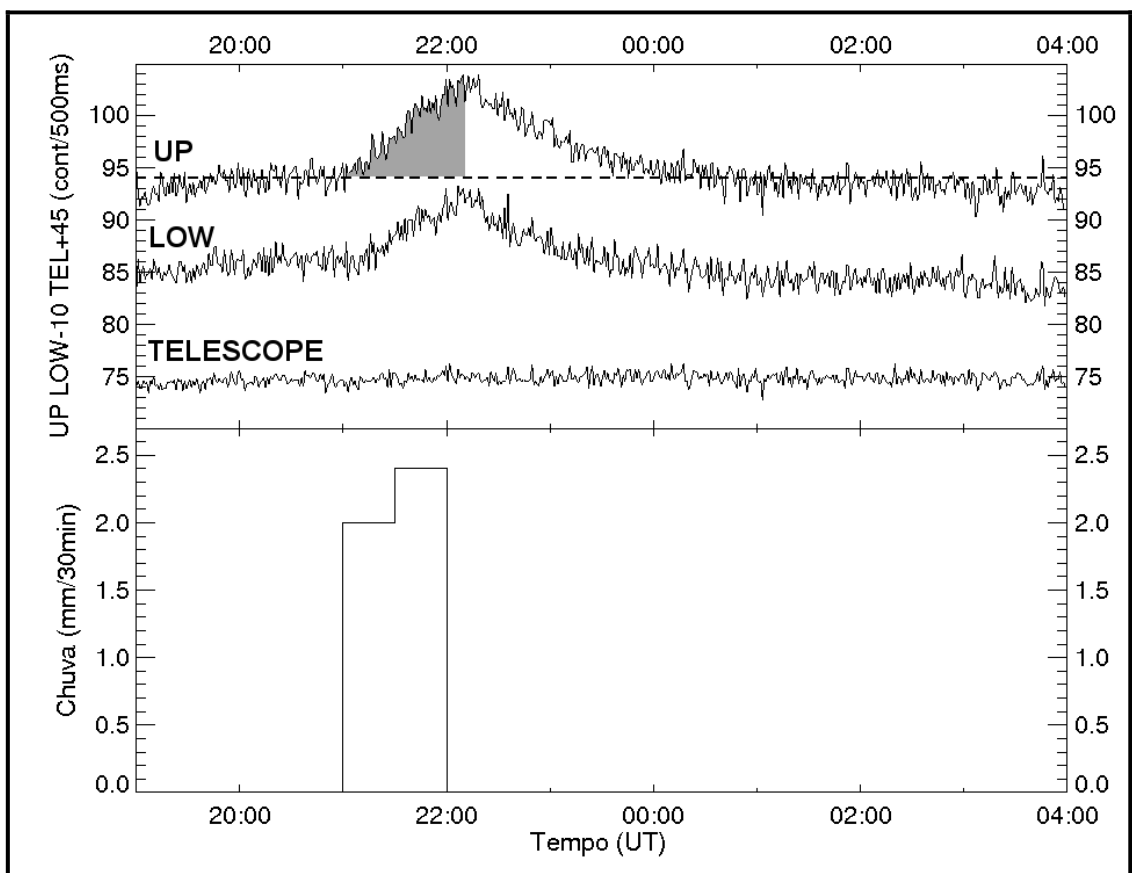

Figura 8 - Exemplo de um evento simples da contagem no sinal UP, LOW e TELESCOPE durante uma chuva. No quadro superior: contagem de raios cósmicos registrada com média de 120 pontos (1 minuto) entre 24/01/2007 às 16:00 UT e 25/01/2007 às 04:00 UT, e no quadro inferior: medida de chuva registrada no mesmo período. Sendo a área cinza corresponde à integral da contagem entre o início e o pico do aumento.

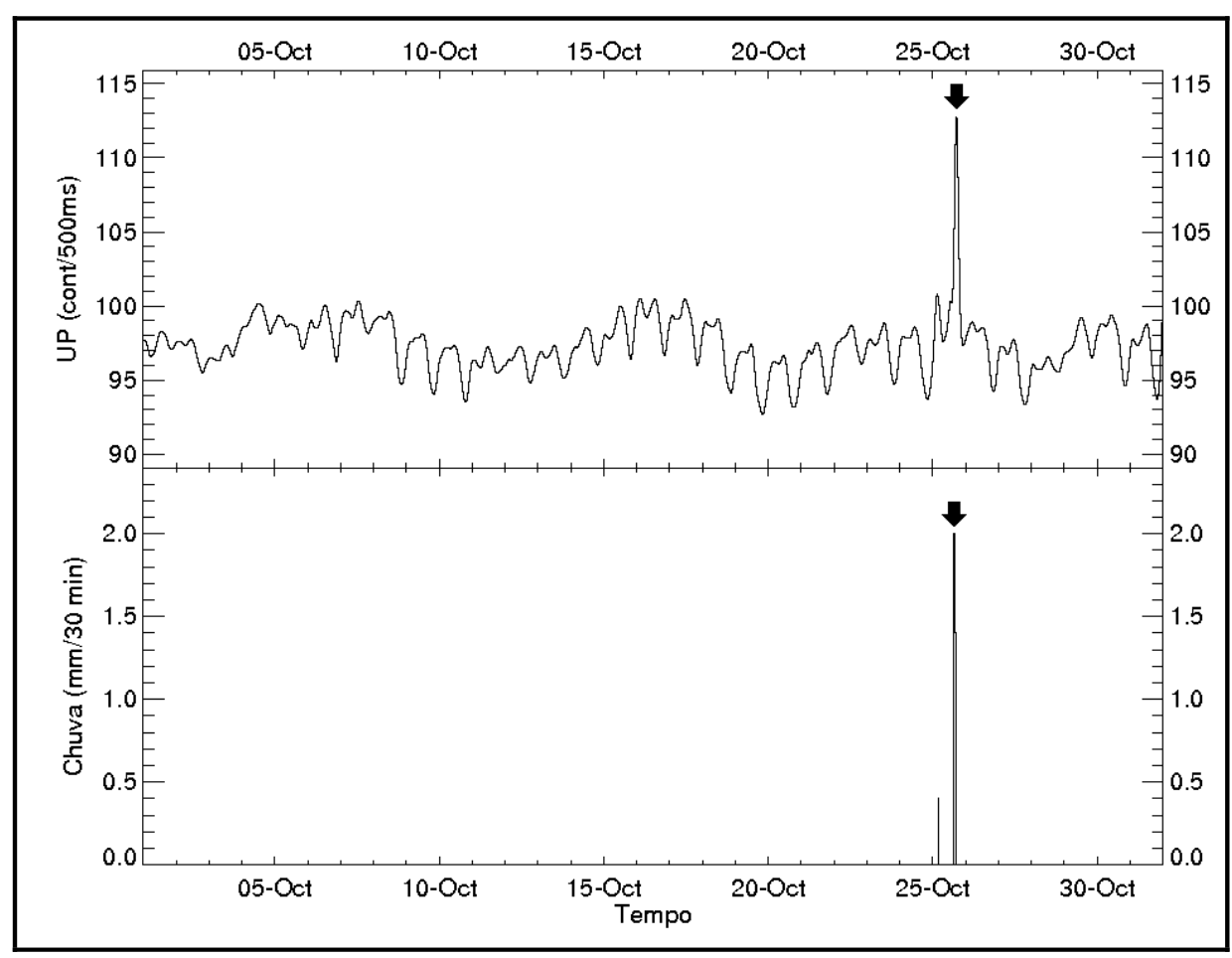

Figura 9 - Quadro superior: média horária da contagem de raios cósmicos registrada no sinal UP no mês de outubro de 2008. Quadro Inferior: medida de chuva em milímetros obtida no mesmo período. 


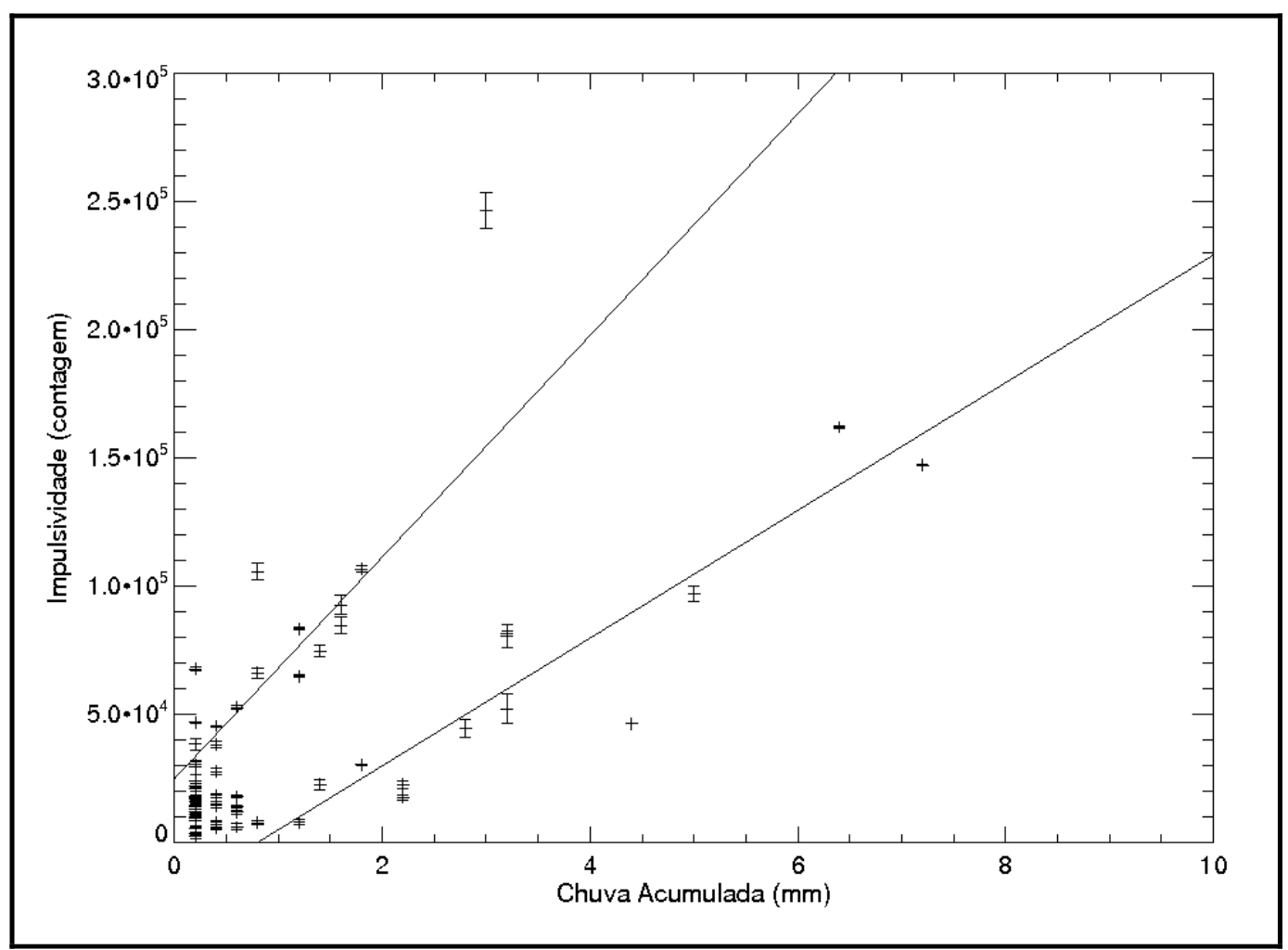

Figura 10 - Correlações encontradas entre a impulsividade da contagem de raios cósmicos e o acúmulo de chuva ocorrido no mesmo período.

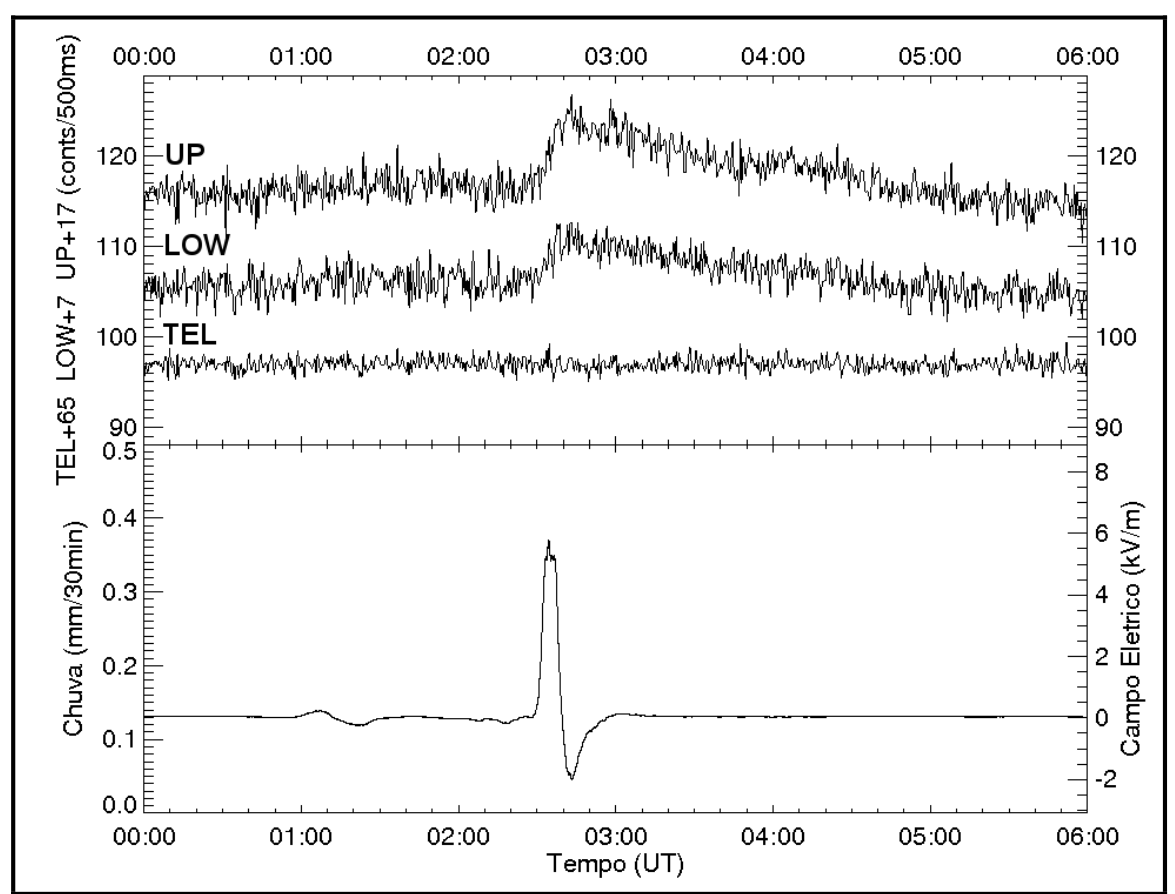

Figura 11 - Variação na contagem registrada pelos sinais UP, LOW e TELESCOPE do CARPET durante uma variação no campo elétrico medido pelo EFM-100 (curva no quadro inferior) sem a ocorrência de chuva (indicada pela falta de histogramas) e sem alterações significativas na contagem do sinal TELESCOPE, entre 30/05/2009 às 00:00 UT e 30/05/2009 às 06:30 UT. 


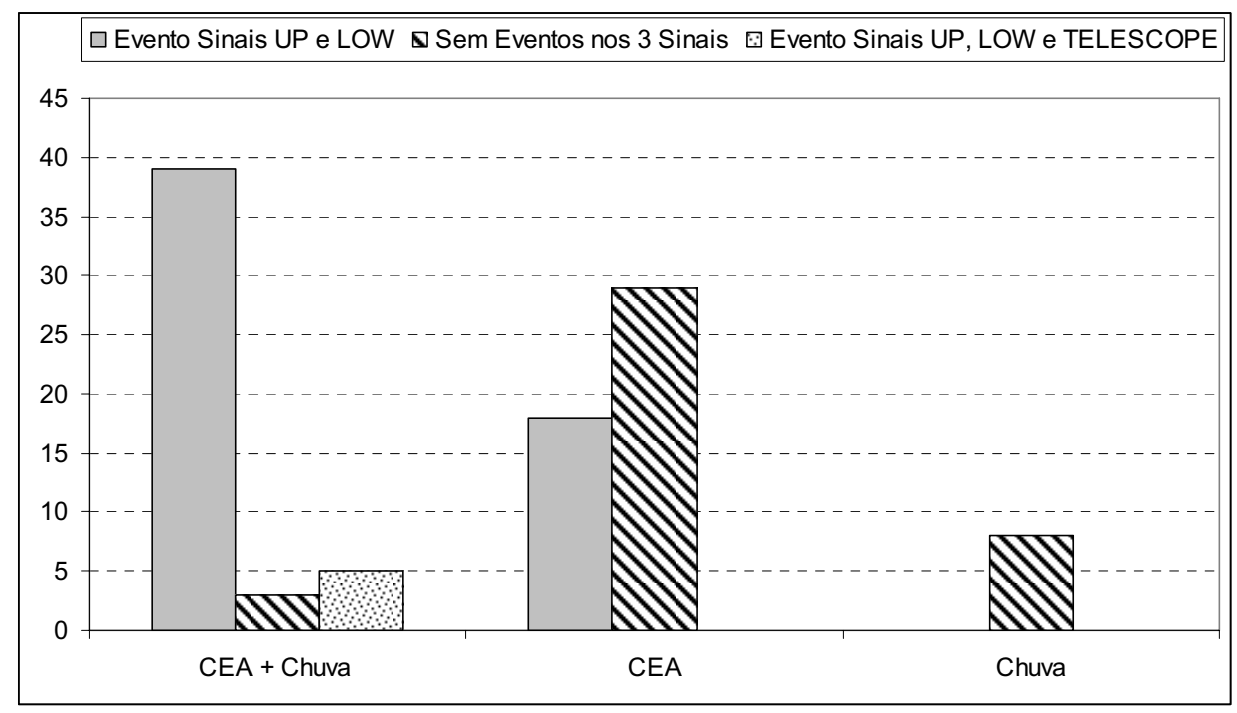

Figura 12 - Número de ocorrências dos diferentes tipos de eventos registrados entre fevereiro de 2008 e dezembro de 2009, mostrando a relação entre a chuva e mudanças no campo elétrico atmosférico, com variações na contagem registradas nos sinais UP, LOW e TELESCOPE do CARPET.

Desde 0 início de 2008, período em que se deu início o monitoramento do campo elétrico atmosférico, diferentes tipos de eventos foram observados. A Figura 12 mostra um histograma com os diferentes tipos de eventos encontrados em uma análise de 102 eventos ocorridos entre fevereiro de 2008 e 2009.

Através deste histograma é possível se observar que nem todas as variações no campo elétrico atmosférico e ocorrência de chuva apresentam variações na contagem de raios cósmicos. É importante notar que não foram observados eventos onde 0 aumento da contagem de partículas cósmicas foi registrado durante períodos sem mudanças significativas no campo elétrico atmosférico, ou seja, todos os eventos de aumento na contagem dos sinais UP e LOW registrados neste período estudado apresentam variações de campo elétrico atmosférico.

Também é possível observar no histograma da Figura 12 que o maior número de eventos se refere àqueles em que só foram observadas variações nas contagens registradas nos sinais UP e LOW ocorridas juntamente com a presença de chuvas e mudanças no campo elétrico atmosférico. Também é significativo o número de eventos em que as variações na contagem desses dois sinais foram observadas em períodos sem chuva, somente com variações no campo elétrico atmosférico. Além disso, é importante notar que foram registrados eventos onde as variações na contagem de raios cósmicos do sinal TELESCOPE que podem estar relacionadas com mudanças no campo elétrico atmosférico, mostrando que elas podem influenciar raios cósmicos de maior energia.

\section{CONCLUSÃO}

Os raios cósmicos são partículas carregadas de altas energias descobertas no início do século XX, que ainda hoje possuem muitos mistérios e ainda são largamente estudadas. 0 fluxo de raios cósmicos registrado na superfície de nosso planeta apresenta diversas variações de longa e curta duração relacionadas com fenômenos solares e do meio interplanetário.

Algumas variações no fluxo de raios cósmicos, relacionadas com fenômenos solares, podem influenciar os fenômenos atmosféricos. Por outro lado, existem variações no fluxo de raios cósmicos que são geradas por fenômenos e processos atmostéricos, como a pressão atmosférica, a emissão de radiação gama pelas chuvas e a aceleração de partículas secundárias pelo campo elétrico da Terra.

0 CARPET é um detector de raios cósmicos que tem como 0 objetivo a observação de variações relacionadas com a atividade solar e com fenômenos da atmosfera terrestre. Tendo, apesar de seu pouco tempo de funcionamento, detectado variações na contagem de raios cósmicos relacionadas com as ejeções de massa coronal, com as explosões solares, e até mesmo com o ciclo solar de 11 anos.

Estudos preliminares de eventos de aumentos na contagem de raios cósmicos, nos dois sinais de menor energia, mostraram que há duas tendências entre 0 aumento na contagem e a quantidade de chuvas. Estas duas tendências podem ser explicadas considerando-se a influência que mudanças no campo elétrico atmosférico têm na intensidade de raios cósmicos registrado pelo CARPET. 
Não há eventos onde os aumentos na contagem de raios cósmicos estão relacionados somente com as chuvas, todos os eventos com chuvas apresentam mudanças no campo elétrico atmosférico. Porém, o contrário não é valido, ou seja, existem casos de aumentos na intensidade de raios cósmicos relacionados somente a mudanças no campo elétrico atmosférico. Isso sugere que os campos elétricos podem apresentar uma maior influência na contagem de raios cósmicos registrada nos sinais de menor energia (UP e LOW) do que 0 aumento da radiação natural ambiente ocorrido durante as chuvas, chegando também a influenciar a contagem registrada no sinal de maior energia (TELESCOPE).

Acredita-se que os raios cósmicos estão fortemente ligados aos fenômenos da atmosfera terrestre. No entanto, a relação entre os raios cósmicos, os fenômenos atmosféricos e os fenômenos solares ainda não é completamente conhecida, sendo assim muito importante 0 estudo das variações na contagem de raios cósmicos em diferentes escalas temporais através da observação por detectores de raios cósmicos, como o CARPET.

\section{AGRADECIMENTOS}

Os autores agradecem à FAPESP (Proc. 2009/11935-5, 2007/ 05630-1 e 2007/52533-1), ao CNPq (Proc. 304433/2004-7, 300211/2008-2 e 550375/2002-3) e ao MACKPESQUISA pelo apoio financeiro.

\section{REFERÊNCIAS}

BAZILEVSKAYA GA, KRAINEV MB \& MAKHMUTOV VS. 2000. Effects of cosmic rays on the Earth's environment. Journal of Atmospheric and Solar-Terrestrial Physics, 62: 1577-1586.

CANE HV. 1996. Cosmic ray decreases: 1964-1994. Journal of Geophysical Research, 101(A10): 561-572.

CANE HV. 2000. Coronal Mass Ejection and Forbush decreases. Space Science Reviews, 93(1-2): 55-77.

DORMAN LI. 2004. Cosmic Rays in the Earth's Atmosphere and Underground. Dordrecht, Holanda: Kluwer Academic Publishers. 855 p.

FAMOSO B, LA ROCCA P \& RIGGI F. 2005. An educational study of the barometric effect of cosmic rays with a Geiger counter. Physics Education, 40(5): 461-467.

FORBUSH SE \& VAN ALLEN JA (Ed.). 1994. Cosmic Rays, the Sun and Geomagnetism: The works of Scott E. Forbush. Washington, USA: American Geophysical Union. 475 p.

JOKIPII JR, LEVY EH \& HUBBARD WB. 1977. Effects of particle drift on cosmic-ray transport. I - General properties, application to solar modulation. Astrophysical Journal, 213: 861-868.
KHAERDINOV NS, LIDVANSKY AS \& PETKOV VB. 2005. Cosmic Rays and the Electric Field of Thunderclouds: Evidence for acceleration of Particles (Runaway Electrons). Atmospheric Research, 76: 346-354.

KUDELA K \& BRENKUS R. 2004. Cosmic ray decreases and geomagnetic activity: list of events 1982-2002. Journal of Atmospheric and Solar-Terrestrial Physics, 66: 1121-1126.

MERIER J-F, TRACY BL, D'AMOURS R, CHANGON F, HOFFMAN I, KORPACH EP, JOHNSON S \& UNGAR RK. 2009. Increased environmental gamma-ray dose rate during precipitation: a strong correlation with contributing air mass. Journal of Environmental Radioactivity, 100: 527-533.

METROPOLIS N \& ULAM S. 1949. The Monte Carlo Method. Journal of the American Statistical Association, 44(247): 335-341.

MURSULA K \& USOSKIN I. 2003. Heliospheric Physics and Cosmic Rays, Lectures Notes. Washington, USA: American Geophysics Union. $168 \mathrm{p}$.

NISHIKAWA T, TAMAGAWA Y \& MIYAJIMA M. 2000. Analysis of environmental gamma-ray intensity increase due to precipitation using EGS4 Monte Carlo simulation code. In: $10^{\text {th }}$ Congress of the International Radiation Protection Association (IRPA 10), 14/05-19/05, 2000, Hiroshima. Proceedings of the IRPA 11 Conference, Hiroshima, Japão: IRPA, 1A, p. 29-35.

OTAOLA JA \& VALDÉS-GALICIA JF. 1992. Los rayos cósmicos: mensajeros de las estrellas. Cidade do México: Fondo de Cultura Económica. $149 \mathrm{p}$.

ROSSI BR. 1964. Cosmic Rays. New York: McGraw-Hill. 268 p.

SINGH YP \& BADRUDDIN. 2006. Effects of the polarity states of the heliospheric magnetic field and particle drifts in cosmic radiation. Solar Physics, 234(2): 339-352.

STOZHKOV YI, ZULLO Jr J, MARTIN IM, PELLEGRINO GQ, PINTO HS, BAZILEVSKAYA GA, BEZERRA PC, MAKHMUTOV VS, SVIRZEVSKY NS \& TURTELLI Jr A. 1995. Rainfalls during great Forbush decreases. Nuovo Cimento, 18C(3): 335-341.

STOZHKOV YI, SVIRZEVSKY NS \& MAKHMUTOV VS. 2001. Cosmic Ray measurements in the Atmosphere. In: Workshop on Ion-AerosolCloud Interactions, 18/04-20/04, 2001, Genebra. Proceedings of the Workshop on Ion-Aerosol-Cloud Interactions (IACI). Genebra, Suíça: CERN, p. 41-62.

SVENSMARK H. 2000. Cosmic rays and Earth's climate. Space Science Reviews, 93(1-2): 175-185.

ZIEGLER JF. 1996. Terrestrial cosmic rays. IBM Journal of R\&D, 40(1): 19-39.

ZIEGLER JF. 1998. Terrestrial cosmic rays intensities. IBM Journal of R\&D, 42(1): 117-140. 


\section{NOTAS SOBRE OS AUTORES}

Rafael Rodrigues Souza de Mendonça. É bacharel em Física pela Universidade Presbiteriana Mackenzie (2008), entre 2006 e 2008 foi estagiário de iniciação cientíica com bolsa FAPESP no Centro de Rádio Astronomia e Astrofísica Mackenzie (CRAAM). Possui mestrado em Geofísica Espacial pelo Instituto Nacional de Pesquisas Espaciais (INPE) e atualmente é aluno de doutorado no mesmo instituto.

Jean-Pierre Raulin. Possui graduação em Física - Université de Paris VI (1984), mestrado em Física e Aplicações - Université de Paris VI (1986) e doutorado em Física de Plasma - Université de Paris VI (1993). Atualmente é professor adjunto associado III da Universidade Presbiteriana Mackenzie. É membro da Sociedade Astronômica Brasileira (SAB), da Royal Astronomical Society (RAS), da Sociedade Brasileira de Microondas e Optoeletrônica (SBM0), e membro eleito da International Astronomical Union (IAU). É coordenador regional e nacional dos programas IHY e ISWI respectivamente, e representante no Brasil da comissão E da URSI. Tem experiência na área de Astronomia, com ênfase em física solar, atuando principalmente nos seguintes temas: radioastronomia, explosões solares, instabilidades de plasma, relações Sol-Terra, física da ionosfera.

Fernando Celso Perin Bertoni. Graduou-se em Física pela Universidade de São Paulo (1994), fez mestrado (1998) e doutorado (2004), em Geofísica Espacial pelo Instituto Nacional de Pesquisas Espaciais, com estágio no Centro de Pesquisas Atmosféricas da Universidade de Massachusetts Lowell, EUA. Atualmente coordena projeto de pós-doutorado no Centro de Rádio Astronomia e Astrofísica Mackenzie (CRAAM), na Escola de Engenharia do Instituto Presbiteriano Mackenzie. Trabalha na área de Física Espacial e Atmosférica com temas relacionados a Rádio-Ciências, Alta Atmosfera Terrestre e Climatologia Espacial.

Ezequiel Echer. Realizou seu doutorado em Geofísica Espacial pelo Instituto Nacional de Pesquisas Espaciais (2003). Atualmente é pesquisador do Instituto Nacional de Pesquisas Espaciais. Realizou pós-doutorado no Instituto Max Planck para Pesquisas do Sistema Solar, Alemanha (2005). Tem experiência na área de Geofísica Espacial, com ênfase em física do meio interplanetário e física de plasmas espaciais, atuando principalmente nos seguintes temas: física de magnetosferas planetárias, origem solar e interplanetária de tempestades geomagnéticas, ondas de plasma na heliosfera e em magnetosferas planetárias.

Vladimir Salingereevich Makhmutov. É pesquisador do Departamento de Física Nuclear e Astrofísica do Instituto de Física P.N. Lebedev da Academia de Ciências da Rússia (LPI-RAS). Vice-diretor do Centro de Física Solar e Raios Cósmicos do LPI. Áreas de interesse: física solar e raios cósmicos, astrofísica, física solar-terrestre, processos atmosféricos e suas relações com fenômenos do meio interplanetário e do espaço próximo à Terra e física experimental.

Germán Fernández. É engenheiro eletrônico formado pela Universidade Nacional de San Juan (1998) na Argentina. Desde 0 ano 2000 trabalha no grupo de eletrônica do Complejo Astronómico El Leoncito (CASLE0), onde se dedica à pesquisa e ao desenvolvimento de tecnologias a serem aplicadas aos telescópios e instrumentos instalados no CASLEO. Trabalha principalmente com placas com microcontroladores programáveis, automatização de telescópios controlados remotamente, além de ser responsável técnico pelas antenas VLF da rede SAVNET (The South America VLF NETwork) presentes no CASLEO e do detector de raios cósmicos CARPET. 